\title{
THE FORCE OF LAW, DE FREDERICK SCHAUER
}

\section{THE FORCE OF LAW, BY FREDERICK SCHAUER}

William Soares Pugliese

Luiz Henrique Krassuski Fortes ${ }^{* *}$

PALAVRAS-CHAVE: Coerção. Elementos Distintivos do Direito. Teoria do Direito.

KEYWORDS: Coercion. Distinctive Elements of Law. Jurisprudence.

Após Playing by the Rules (SCHAUER, 1991) e seu mais recente Thinking Like a Lawyer (SCHAUER, 2009), Frederick Schauer publicou, no primeiro semestre de 2015, obra inédita denominada The Force of Law. À primeira vista, a expressão pode levar o leitor a vislumbrar um diálogo com textos mais conhecidos dos juristas brasileiros, como os de Jacques Derrida (2007) e Giorgio Agamben (2004) - mas o assunto enfrentado por Schauer é bastante distinto.

O autor não esconde, desde as primeiras linhas, que seu objetivo ao iniciar a redação do livro era desafiar a noção defendida por Herbert L. A. Hart, em The Concept of Law (2012), de que a natureza do Direito não engloba o elemento coercitivo. Em outras palavras, a intenção de Schauer é resgatar a investigação do papel da força nos sistemas jurídicos ou retomar o estudo da coerção, há muito abandonada pela Teoria do Direito na tradição pós-hartiana ${ }^{1}$. Por consequência, o autor também se propõe a desafiar os métodos da Teoria do Direito contemporânea, por razões que se tornam claras ao longo da leitura da obra.

\footnotetext{
* Doutorando em Direitos Humanos e Democracia pelo Programa de Pós-Graduação da Faculdade de Direito da Universidade Federal do Paraná. Mestre em Direito das Relações Sociais pelo Programa de Pós-Graduação da Faculdade de Direito da Universidade Federal do Paraná. Coordenador da Pós-Graduação em Direito Processual Civil (Novo CPC) da Academia Brasileira de Direito Constitucional (ABDConst). Professor Adjunto de Direito Processual Civil das Faculdades Integradas do Brasil (UNIBRASIL). Membro da Comissão de Educação Jurídica da OAB/PR. Advogado. E-mail: wpugliese@gmail.com

** Mestre em Direito das Relações Sociais pelo Programa de Pós-Graduação em Direito da Universidade Federal do Paraná. Membro do Grupo de Pesquisa Interdisciplinar em Justiça Eletrônica e-Justiça (CNJ-CAPES-UFPR). Bacharel em Direito pela FD-UFPR. Especialista em Direito Constitucional pela Academia Brasileira de Direito Constitucional (ABDConst). Assessor na Justiça Federal em Curitiba - Paraná (TRF4). E-mail: krassuski@gmail.com

${ }^{1}$ Não se pode ignorar, porém, o papel central da coerção na tradição continental europeia, em especial no pensamento de Hans Kelsen, com quem Herbert Hart desenvolveu rico debate no plano teórico. Não é por outra razão que esse autor disse, em trecho amplamente debatido: "The law is, to be sure, an ordering for the promotion of peace, in that it forbids the use of force in relations among the members of the community. Yet, it does not absolutely preclude the use of force. Law and force must not be understood as absolutely at the variance with one another. Law is an organization of force. For the law attaches certain conditions to the use of force in relations among men, authorizing the employment of force only by certain individuals and only under certain conditions” (KELSEN, 1949, p. 21).
} 
Os capítulos iniciais do livro procuram rememorar a bibliografia clássica que via no papel coercitivo o traço distintivo do Direito. Trata-se, em síntese, dos nomes a quem Hart direcionou suas principais críticas: Bentham e Austin. Apesar de identificar teses interessantes e razoavelmente válidas, Schauer confessa não ter argumentos contra a tese de Hart - ainda mais aprofundada nos últimos anos por autores como Scott Shapiro $(2011)^{2}$ - no sentido de que a coerção não é um traço distintivo do Direito. O autor reconhece esta situação, pois para ele também é possível conceber um sistema no qual o Direito se desenvolve sem coerção. O problema, porém, é que sistemas como estes só se verificam em teoria.

Nas palavras do autor, definir um conceito excluindo tudo que não lhe é comum acaba por esgotar o próprio conceito. Dizer, assim, que a coerção não integra o conceito de Direito é como dispensar a característica de voo das aves, simplesmente porque pinguins não tem a habilidade de voar. Proceder desta forma significa excluir um traço evidentemente distintivo de um conceito porque ele não está presente em um caso periférico.

Para cumprir o objetivo proposto, Schauer resgata o personagem de Hart batizado de “puzzled man”, ou seja, a pessoa que deseja saber a conduta indicada pelo Direito não porque procura evitar problemas, mas sim porque deseja agir conforme o Direito. A partir deste personagem Hart e seus seguidores concluem que a coerção não desempenha um papel definitivo para o Direito na perspectiva do observador interno.

O problema, para Schauer, é que esta não é a pergunta feita pelo verdadeiro "puzzled man”. O autor demonstra que a questão que efetivamente implica resultados concretos para a definição do Direito é se uma pessoa que chega a uma conclusão após considerar "tudo menos o direito” irá mudar seu entendimento apenas por conta da existência de uma regra jurídica sem sanção. ${ }^{3}$ Empiricamente, é demonstrado na obra que a resposta é majoritariamente negativa.

A constatação é a de que as pessoas tendem a agir de modo diferente, ou seja, em contrariedade ao Direito, se com ele não concordam e não há sanção que busque efetivá-lo. A coerção, ainda, é vital para definir padrões de conduta tanto do cidadão como autoridades estatais, ainda que seus atos fujam da legalidade com a melhor das intenções, pois isto significaria uma indesejada discricionariedade. Nas palavras do autor (2015, p. 92), “uma constituição existe, em parte, para evitar que oficiais do Estado façam coisas ruins, mas também, e mais importante, existe

\footnotetext{
${ }^{2}$ É possível traçar o gérmen das reflexões de Schauer sobre a importância da coerção na Teoria do Direito em artigo publicado no Yale Law Journal (2010) em que dialoga diretamente com a teoria de Shapiro, e no qual conclui que as dimensões coercitivas do Direito proveem um campo frutuoso para a investigação teórica e filosófica.

3 "The question now is whether people, when they have reached this all-things-except-the-law-considered judgment, will, sanctions aside, subjugate that judgment to the prescriptions of the law.” (SCHAUER, 2015, p. 62).
} 
para evitar que bons oficiais façam o que eles acham que são coisas boas, ou que podem até mesmo ser coisas boas a curto prazo, em detrimento do interesse público a longo prazo”. 4

Também se argumenta que a coerção é o único elemento do Direito utilizado até mesmo pelas mais avançadas democracias para garantir a observância de suas próprias normas. Evidentemente, a coerção também é um dos poucos elementos presentes nos ordenamentos mais autoritários - que não são defendidos, mas nem por isso deixam de ser analisados pelo autor para demonstrar seus pontos de vista.

Tudo isso leva Schauer a apontar para a onipresença da coerção. Para o autor, é o elemento coercitivo, com exceção dos sistemas concebidos apenas em teoria, que distingue o Direito dos demais sistemas normativos e de outros mecanismos de organização social. Aqui vale relembrar o objetivo secundário do livro, de desafiar a metodologia da Teoria do Direito: a metodologia de Schauer procura observar a realidade e retratar os sistemas jurídicos reais. É, assim, no sentido de se abandonar uma teoria afastada da realidade, que se pode compreender o desafio metodológico proposto.

Por consequência, o desenvolvimento dos argumentos da obra também se mostram suficientes para a consecução do objetivo principal estabelecido em seu início: apesar de a coerção não ser necessária para a definição de um sistema jurídico, por outro lado é, em teoria, um elemento imprescindível do Direito verificado na prática. Mais do que isso, a coerção é o elemento que confere força ao Direito, daí a razão para o título da obra.

Como conclusão, o livro sustenta que existem diversos critérios que distinguem o Direito de outros modos de regulação e organização social, dentre eles o sociológico, o procedimental, o metodológico e o critério de fontes. Mas o autor defende um novo critério (ou a sua revisão): o coercitivo, justamente porque é o Direito que regula e legitima o uso da força e dela se vale incessantemente.

Da leitura da obra de Schauer não se extrai uma definição completa e íntegra para o fenômeno jurídico. Também não se identificam todas as respostas para questões pulsantes no Direito brasileiro. Mas não é este o propósito da obra. Ao provar, teórica e empiricamente, que a coerção é um elemento verificado em todo sistema jurídico contemporâneo, o autor pretende resgatar a importância deste elemento para a discussão jurídica, algo que há muito tem sido deixado de lado pelos teóricos do Direito, que, em sua ótica, majoritariamente não têm cumprido a tarefa de proporcionar a melhor compreensão do fenômeno jurídico.

\footnotetext{
${ }^{4}$ Tradução livre de "a constitution exists in part to keep bad officials from doing bad things, but it also, and more importantly, exists to keep good officials from doing what they think are good things, or may even be good things in the short run, to the detriment of the long run public interest."
} 
O que The Force of Law proporciona ao leitor é, na verdade, uma caixa de ferramentas destinada à compreensão do elemento coercitivo para o Direito, tanto para o cidadão comum, quanto para as autoridades do Estado - inclusive os juízes. Com isso, reacende-se o antigo debate em termos contemporâneos, pois há coerção não apenas sobre os particulares, mas também sobre os oficiais do Estado e sobre os entes públicos, o que se revela um importante argumento contra a discricionariedade. Nas palavras do autor (2015, p. 168),

\begin{abstract}
focar no aspecto coercitivo do direito nos ajuda a compreender por que e quando talvez precisemos dele, bem como por que e quando o direito pode fazer coisas que outras instituições políticas e demais formas de organização social não conseguem. [...] Se nós ignorarmos ou não dermos atenção a essa capacidade, ou mesmo pensarmos que investigála não faz parte de um empreendimento teórico ou filosófico, talvez percamos algo da compreensão do direito que nos auxilia a perceber quando utilizá-lo é sábio - e quando não é. $^{5}$
\end{abstract}

\title{
REFERÊNCIAS
}

AGAMBEN, Giorgio. Estado de Exceção. São Paulo: Boitempo, 2004.

DERRIDA, Jacques. Força de Lei. São Paulo: WMF Martins Fontes, 2007.

HART, Herbert. L. A. The Concept of Law. New York: Oxford University Press, 2012.

KELSEN, Hans. General Theory of Law and State. Cambridge: Harvard University Press, 1949.

SCHAUER, Frederick. Playing by the rules: A Philosophical Examination of Rule-Based DecisionMaking in Law and in Life. New York: Oxford University Press, 1991.

. The Best Laid Plans. The Yale Law Journal, New Haven, v. 120, p. 586-621, 2010.

. The Force of Law. Cambridge: Harvard University Press, 2015.

. Thinking like a lawyer. Cambridge: Harvard University Press, 2009.

SHAPIRO, Scott J. Legality. Cambridge: The Belknap Press of Harvard University Press, 2011.

\footnotetext{
${ }^{5}$ Tradução livre de: "focusing on the coercive side of law helps us to understand why and when we might need law, and why and when law can do things that other political institutions and other forms of social organization cannot. [...] if we ignore or slight that capacity [law's coerciveness], or even think that exploring it is not part of a theoretical or philosophical enterprise, we may lose some of the understanding of law that helps us to see when using law is wise and when it is not.”
} 


\section{THE FORCE OF LAW, BY FREDERICK SCHAUER}

KEYWORDS: Coercion. Distinctive Elements of Law. Jurisprudence.

Recebido: 19 de maio de 2015

Aprovado: 12 de junho de 2015 